\title{
ГРАНИЦЫ СУБЪЕКТОВ РОССИЙСКОЙ ФЕДЕРАЦИИ: ПОНЯТИЕ, СТАТУС, ФУНКЦИИ, ПРАВОВОЕ ЗАКРЕПЛЕНИЕ
}

\begin{abstract}
Аннотация: Статья посвящена исследованию понятия границ субъектов Российской Федерации, их правого статуса и фукниий.Основное внимание уделяется вопросам правового закрепления границ субъектов Российской Федераичи. Автором предлагается осущчествлять правовое закрепление грании между субъектами Российской Федерации в тексте специильного закона субъекта Российской Федерации и приложениях к нему с подробным описанием и картографическими материалами в случае, если прохождение границы не вызывает споров у сопредельных субъектов и совпадает в их законодательстве. В случае возникновения спора правовое закрепление предлагается осуществить в соглашении между субъектами Российской Федерации, утвержденном Советом Федерации Федерального Собрания Российской Федерации.

Ключевые слова: Юриспруденияи, Федерализм, Субъект, Гранииа, Территория, Закон, Статус, Конституичия, Делимитацчия, Демаркащия
\end{abstract}

«Русском толковом словаре» значение слова «граница» определено как линия раздела между территориями ${ }^{1}$. В целом определение данного понятия как линии раздела между территориями государств, различных территориальных единиц государства может быть положено в основу юридического определения. Тем не менее оно нуждается в конкретизации исходя из специфики правового статуса той или иной границы.

В Российской Федерации границы публично-территориальных образований, в пределах которых осуществляется публичная власть непосредственно населением и органами публичной власти, представляют собой Государственную границу Российской Федерации, границы субъектов Российской Федерации, границы муниципальных образований и границы административнотерриториальных единиц субъектов Федерации. При этом с Государственной границей могут совпадать все иные виды границ (субъектов Российской Федерации, муниципальных образований, административно-территориальных единиц). Граница субъекта Российской Федерации является частью Государственной границы России либо границей иного субъекта Федерации, а также границей муниципального образования и административно-территориальной единицы (которые могут совпадать территориально) данного и сопредельного субъекта Федерации.

Границы определяют пределы осуществления публичной власти соответствующего уровня, не позволяют вторгаться властным органам сопредельного территориального образования. В этом основная цель установления границ. Из достижения данной цели исходит и энциклопедическое

1 Лопатин В.В., Лопатина Л.Е. Русский толковый словарь. M., 1997. C. 108. определение границы государства, в частности, данное в энциклопедическом словаре Ф.А. Брокгауза» И.А. Ефрона: «Границами смежных государств определяются пределы территориального верховенства каждого из них; поэтому они должны быть точно определены, в виду предупреждения столкновений и недоразумений. Различают границы физические (моря, реки, горные хребты) и договорные или условные. Одного такого существования физических границ еще недостаточно: они должны быть признанны таковыми»². В отношении границ субъектов Российской Федерации (как и иных федеративных государств) отметим, что границы между ними также устанавливаются для ограничения территориальных пределов реализации их компетенции, включая действие региональных нормативных правовых актов и деятельность органов государственной власти, во избежание предупреждения столкновений и недоразумений с сопредельными субъектами и оптимизации взаимодействия с федеральным центром.

Границы территории государства, в частности Российской Федерации, должны быть международно признанными и международно установленными. Граница государственной территории Российской Федерации определена действующими международными договорами и законодательными актами, включая действующие акты бывшего СССР. Границы субъектов Российской Федерации также должны быть признаны как федеральным центром, так и регионами. Их прохождение закрепляется в законодательных актах государства, как федерального, так и регионального уровня, а также устанавливаются на местности.

\footnotetext{
2 Энциклопедический словарь, том IX / Издатели: Ф.А.Брокгауз, И.А.Ефрон, Санкт-Петербург, 1898. С.559.
} 
В юридической литературе границы государств определяются как линии, обозначенные на картах (а при малейшей возможности и на местности), и проходящие по этим линиям вертикальные поверхности до границы земного пространства с космосом, с одной стороны, и с другой стороны - до центра Земли в глубь ее недр, а практически - на доступную для проникновения в недра глубину ${ }^{3}$.

Сходное понятие государственной границы сформулировано в статье 1 Закона Российской Федерации от 1 апреля 1993 года «О Государственной границе Российской Федерации»: Государственная граница Российской Федерации - есть линия и проходящая по этой линии вертикальная поверхность, определяющие пределы государственной территории (суши, вод, недр и воздушного пространства) Российской Федерации, то есть пространственный предел действия государственного суверенитета Российской Федерации.

В свою очередь, в российском законодательстве отсутствует определение понятия «граница между субъектами Российской Федерации», хотя само оно широко используется в законодательстве (например, в Земельном кодексе Российской Федерации, Градостроительном кодексе Российской Федерации и т.д.) и подзаконных нормативных правовых актах.

По аналогии с законодательным определением Государственной границы Российской Федерации в законах об административно-территориальном устройстве ряда субъектов Федерации устанавливается понятие внутренних административных границ субъектов Федерации, в частности, граница административно-территориальной единицы - линия и проходящая по этой линии вертикальная поверхность, определяющие пределы территории административно-территориальной единицы и отделяющие состав территории административно-территориальной единицы от составов территорий других административно-территориальных единиц (Башкортостан, Бурятия и др.), либо такое понятие не устанавливается вовсе.

Вместе с тем в силу прямого установления ч. 1 ст. 67 Конституции РФ воздушное пространство не входит в состав территории субъекта Российской Федерации. Кроме того, отнесение большей части недр к территории субъекта Федерации весьма спорно. Значит, подобное определение неправомерно, поскольку проходящая по линии границы вертикальная поверхность не может отделять территорию субъекта Федерации и, тем более, территорию его административно-территориальной единицы или муниципального образования. Названные границы разделяют лишь поверхность территории, следовательно, прямые аналогии в определении внутрен-

3 Уиаков Н.А. Международное право: основные термины и понятия. М.: ИГЛ РАН. 1996. С. 37. них границ с определением Государственной границы неправомерны. В законодательстве об административно-территориальном устройстве многих субъектов Российской Федерации определение дано корректно. Границей административно-территориального образования определяется закрепленная в установленном порядке линия, определяющая пределы территории административно-территориального образования (например, в Алтайском крае, Владимирской области).

Согласимся с предлагаемыми в литературе определениями понятия «граница административно-территориальной единицы субъекта Российской Федерации» - как линия, определяющая пределы административно-территориальной единицы субъекта Российской Федерации и отделяющая состав территории административно-территориальной единицы от составов территорий других административно-территориальных единиц; понятия «граница субъекта Российской Федерации» - как линия, определяющая пределы территории субъекта Российской Федерации и отделяющая состав территории субъекта Российской Федерации от составов территорий других субъектов Российской Федерации ${ }^{4}$.

Границы муниципального образования устанавливаются законами субъектов Российской Федерации в соответствии с требованиями, определенными Федеральным законом от 6 октября 2003 г. «Об общих принципах организации местного самоуправления в Российской Федерации». Данный Федеральный закон не установил официального определения понятия «граница муниципального образования». Полагаем, что это целесообразно сделать именно в данном Федеральном законе. За основу можно взять приведенный выше подход и определить понятие «граница муниципального образования» как линия, определяющая пределы муниципального образования и отделяющая состав территории муниципального образования от составов территорий других муниципальных образований.

Определение понятия «границы между субъектами Российской Федерации» неустановленно в законодательстве. Его поиск может быть связан с урегулированием ее статуса. Из ч. 3 ст. 67 Конституции РФ следует, что территории субъектов Федерации имеют границы. В литературе отмечается, что они являются административными ${ }^{5}$. Но субъекты Российской Федерации не являются административно-территори-

\footnotetext{
${ }^{4}$ Чертков А.Н. Правовое регулирование территориального устрйоства России: концепция и прогноз. Дис. ... доктора юрид. наук. M., 2012. C. 279.

${ }^{5}$ Например, Постатейный комментарий к Конституции Российской Федерации / Под общ. ред. Ю.В. Кудрявцева. - М., 1996; Орлова М.Ф. Территория и границы субъекта Российской Федерации (на примере Астраханской области). Дис. ... канд. юрид. наук. М., 2002.
} 


\section{Право и политика 1 (157) 2013}

альными единицами. Они являются государственнотерриториальными единицами, а республики прямо определены в Конституции РФ как государства. Присоединимся к позиции, согласно которой более корректно было бы не называть границы субъекта Российской Федерации ни административными, ни государственными. Это внутренние границы, определяющие пространственные пределы территории субъектов Российской Федерации - территориальных единиц, чей правовой статус определен Конституцией РФ и конституциями (уставами) субъектов Федерации. Предлагаемое наименование - «границы субъекта Российской Федерации» ${ }^{6}$.

Важным аспектом определения статуса границы выступают источники ее правового закрепления. Фактически Государственной границей Российской Федерации стала граница РСФСР, частично совпадающая с границей СССР. Нормативно ее прохождение закреплено в действующих международных договорах бывшего СССР и, отчасти, Российской Федерации, а также и законодательных актах Российской Федерации и СССР в части непротиворечащей законодательству России. Законом Российской Федерации «О Государственной границе Российской Федерации» определяется установление и изменение прохождения Государственной границы. Прохождение Государственной границы устанавливается и изменяется международными договорами Российской Федерации, федеральными законами. Документы об изменениях, уточнениях прохождения Государственной границы на местности, произведенных в порядке проверки Государственной границы на основании международных договоров Российской Федерации, вводятся в действие в соответствии с законодательством Российской Федерации (часть 1 статьи 5).

Установление и изменение Государственной границы Российской Федерации, установление и поддержание отношений с сопредельными иностранными государствами, а также регулирование общественных отношений на приграничных территориях (акваториях) Российской Федерации и на путях международных сообщений, пролегающих на российской территории, осуществляется на основе принципов: обеспечения безопасности Российской Федерации и международной безопасности; взаимовыгодного всестороннего сотрудничества с иностранными государствами; взаимного уважения суверенитета, территориальной целостности государств и нерушимости государственных границ; мирного разрешения пограничных вопросов (статья 2).

${ }_{6}^{6}$ Чертков А.Н. Указ. соч. - С. 279.
Аналогичные принципы распространяются на установление и прохождение границ субъектов Российской Федерации, совпадающих с участками Государственной границы России. При этом основными принципами установления и изменения границ между субъектами Российской Федерации могут выступать: обеспечение единства территории субъекта Федерации и территории России; неотчуждаемость территории субъекта Российской Федерации от территории России; безопасность территории Российской Федерации и ее субъекта; единство правового, политического, социально-экономического и иных пространств Российской Федерации, в том числе свободного передвижения населения, товаров и услуг через границы субъектов Федерации; взаимовыгодное всестороннее межрегиональное сотрудничество; взаимное уважение статуса и границ между субъектами Российской Федерации; невозможность изменения границ между субъектами Российской Федерации иначе как по их взаимному согласию; правомерное и согласованное разрешение споров относительно прохождения границы.

В соответствии с действующим законодательством прохождение Государственной границы, если иное не предусмотрено международными договорами Российской Федерации, устанавливается:

a) на суше - по характерным точкам, линиям рельефа или ясно видимым ориентирам;

б) на море - по внешнему пределу территориального моря Российской Федерации;

в) на судоходных реках - по середине главного фарватера или тальвегу реки; на несудоходных реках, ручьях - по их середине или по середине главного рукава реки; на озерах и иных водоемах - по равноотстоящей, срединной, прямой или другой линии, соединяющей выходы Государственной границы к берегам озера или иного водоема.

Государственная граница, проходящая по реке, ручью, озеру или иному водоему, не перемещается как при изменении очертания их берегов или уровня воды, так и при отклонении русла реки, ручья в ту или иную сторону;

г) на водохранилищах гидроузлов и иных искусственных водоемах - в соответствии с линией Государственной границы, проходившей на местности до ее затопления;

д) на мостах, плотинах и других сооружениях, проходящих через реки, ручьи, озера и иные водоемы, - по середине этих сооружений или по их технологической оси, независимо от прохождения Государственной границы на воде (часть 2 статьи 5).

Различают сухопутные, водные и воздушные границы государственной территории. Режим государственной границы предполагает наличие нескольких условий, а именно; 
а) сохранность территории государства;

б) международное признание;

в) международное установление 7

Изложенные подходы не могут быть взяты за основу при регламентации установления и изменения границ субъектов Российской Федерации. Во-первых, субъекты Федерации хотя и обладают всей полнотой государственной власти на своей территории, но эта полнота охватывает лишь сферы, остающиеся за рамками предметов ведения и полномочий Российской Федерации по предметам совместного ведения. Как отмечалось выше, субъекты Российской Федерации не обладают государственным суверенитетом. Территория и границы субъекта Федерации не имеют правового режима территории и границ суверенного государства.

Во-вторых, на границы субъектов Федерации не распространяются принципы международного признания, не требуется и международно-правового регулирования их установления и изменения. Рассматриваемый вопрос - сугубо внутреннее дело Российской Федерации. Хотя правовое оформление границ территории субъекта Российской Федерации также осуществляется через процедуры их признания и установления. Но признание будет не международным, а внутригосударственным. Государственно признанными границами субъектов Федерации будут являться линии разграничения сухопутной государственной территории, отграничивающие территорию субъекта Федерации от территорий с другим правовым режимом (в частности, территория другого субъекта Федерации, территориальное море), прохождение которых согласовано с сопредельными субъектами Федерации.

В-третьих, как отмечалось выше, в состав территории субъекта Российской Федерации не входит воздушное пространство, следовательно, у субъектов Федерации не может быть воздушных границ. В отношении недр также отмечалось, что лишь некоторая часть недр неглубокого залегания может однозначно рассматриваться как территория субъекта Федерации. Если же принять бассейновый подход к управлению, использованию и охране водных объектов, то излишним становится установление границ субъектов Федерации по акваториям водных объектов. Тем более они не устанавливаются по пределам территориального моря России. Исключение необходимо сделать для мостов, плотин и других сооружений, определяя границы по середине этих сооружений или по их технологической оси, а также водохранилищ, гидроузлов и иных искусственных водоемов, определяя границы субъектов Федерации в соответствии с линией их границы, проходившей на местности до ее затопления, в случае, если данные объекты не относятся к федеральной

${ }^{7}$ Подробнее: Клименко В.М., Порк А.А. Территория и граница CCCP. 1985. C. 61-71. собственности и управляются непосредственно федеральными органами. Региональное значение, ведение и собственность на данные объекты предполагает разграничение сфер компетенции и ответственности, а также объектов собственности между сопредельными субъектами Российской Федерации.

В ряде основных законов субъектов Российской Федерации подчеркивается, что в границы субъекта Федерации включаются административно-территориальные единицы, образующие его территорию. В Уставе Приморского края установлено, что официальным документом, закрепляющим границы субъекта Федерации, являются: на участках границы субъекта, являющихся участками Государственной границы Российской Федерации, - международные договоры Российской Федерации, федеральные законы; на участках границы между субъектами Российской Федерации - картографические материалы и описание границы, заверяемые подписями уполномоченных для этой цели должностных лиц в соответствии с законодательством субъектов Российской Федерации (в частности, Губернатор Приморского края).

В отношении границ, совпадающих с Государственной границей Российской Федерации, изложенное справедливо безотносительно того, содержится ли соответствующее положение в законодательстве субъекта Российской Федерации или нет. Задача субъекта Российской Федерации - надлежащее правовое оформление прохождения границы между субъектами Российской Федерации, которая в настоящее время не решена.

В связи с изложенным важно отметить, что понятие «границы субъекта Российской Федерации» шире понятия «границы между субъектами Российской Федерации». К сожалению, в литературе и даже законодательстве данные понятия не всегда различаются. Но, очевидно, что сухопутной границей субъекта Российской Федерации может быть и участок Государственной границы Российской Федерации. Происходит их пространственное совпадение, но не совпадение правового статуса. В свою очередь границы между субъектами Российской Федерации представляют собой те границы, которые разделяют территории субъектов Российской Федерации и не включают участки Государственной границы Российской Федерации.

Практическое значение данных терминологических изысканий видится в следующем. В отношении границы субъекта Российской Федерации, совпадающим с участком Государственной границы России, органам государственной власти субъекта Федерации остается лишь перенести из положений федеральных нормативных правовых актов, содержащих описание данного участка границы, в собственное описание соответствующей границы. Каких либо возражений или споров со стороны других субъектов Федерации прохождение данной границы не вызовет в принципе, а отсутствие надлежащего 


\section{Право и политика 1 (157) 2013}

правового оформления прохождения соответствующей границы субъекта Федерации не повлечет правовой неопределенности в отношении реализации прав и свобод граждан, хозяйственной и иной деятельности на данной территории. Правовой режим Государственной границы России определяет такие вопросы достаточно полно. В свою очередь, от качества регионального правового оформления прохождения границы между субъектами Федерации зависит реализация прав и свобод граждан, различные виды разрешенной законом деятельности, взаимоотношения между субъектами Федерации. Федеральное законодательство в настоящее время не решает соответствующие вопросы. При этом участие Федерации в создании и обеспечении правового режима границ между субъектами Российской Федерации объективно ограниченно. Даже при его усилении именно от субъектов Российской Федерации зависит законность и правопорядок в рассматриваемом вопросе.

В литературе выделяют следующие базовые функции государственной границы:

a) определение принадлежности территории государственно организованному народу;

б) определение пространственной юрисдикции (соответствующего государства, его органов и институтов, межгосударственных объединений, в которые входит государство, а также пределов нераспространения юрисдикции других государств);

в) определение пространственных пределов размещения национальных институтов (политической системы общества, национальной экономики и т.д.),

г) признание государства, принадлежности ему соответствующей территории, юрисдикции его органов (международное сообщество и национальная общность признают, что данная территория принадлежит государству, а за ее пределами начинаются территории с иным правовым режимом);

д) информирование (о том, что начинается территория и, следовательно, юрисдикция данного государства);

е) предостережение (от незаконного перемещения через границу, нарушения ее режима);

ж) охрана территории (граница представляет собой естественный или искусственно созданный объект, оборудованный и охраняемый в целях защиты территории государства, официального оформления пределов государственной территории на местности, определения на местности пределов действия пограничного правового режима) ${ }^{8}$.

Очевидно, что и границы субъектов Российской Федерации выполняют в чем-то аналогичные функции с учетом внутригосударственного характера таких границ.

8 Чертков А.Н. Указ. Соч. С. 435-436.
1) определение принадлежности территории публичному коллективу - населению субъекта Российской Федерации как части народа России;

2) определение территориальных пределов осуществления государственной власти на уровне определенного субъекта Российской Федерации (включая его население, органы власти), а также пределов нераспространения компетенции других субъектов;

3) определение пространственных пределов размещения региональных институтов, инфраструктуры и иных объектов субъекта Федерации;

4) признание принадлежности субъекту Российской Федерации соответствующей территории, юрисдикции его органов (Российская Федерация и субъект Федерации признают, что данная территория принадлежит данному субъекту, а за ее пределами начинаются территории под юрисдикцией иных публично-территориальных образований);

5) информирование неопределенного круга лиц (населения, органов публичной власти, общественных объединений) о начале и прекращении юрисдикции субъекта Федерации;

6) предостережение (от нарушения правового режима территории, нарушения целостности территории субъекта Федерации и целостности территории России);

7) охрана территории может рассматриваться в отношении субъектов Федерации в весьма усеченном виде и включает, главным образом, защиту официального оформления пределов территории субъекта Федерации на местности, а также обеспечение согласованности изменения границ в соответствии с законодательством.

Важно отметить неправомерность и фактическую невозможность распространения на режим границ субъектов Федерации режима Государственной границы России. К границам субъектов Федерации применимы лишь самые общие подходы, используемые при установлении и изменении Государственной границы. Так, принцип: «Не допускается любой пересмотр границ», за исключением «незначительных частных изменений» при соблюдении одновременно определенных условий, может быть применен лишь с учетом внутригосударственного характера таких границ. Речь идет о недопустимости изменения границ субъекта Российской Федерации без его согласия, выраженного в соответствии с законодательством Российской Федерации, при условии, что изменение прохождения границы не нанесет ущерба безопасности, единству и территориальной целостности России.

В то же время, очевидно совпадение базовых функций и значения границ субъектов Российской Федерации и Государственной границы России с учетом внутригосударственного характера границ субъектов. Границы определяют территорию государственного образования и все, что связано с ее статусом и развитием. На это ука- 
зывает приведенные выше функции границ субъектов Российской Федерации, сформулированные с опорой на функции государственной границы.

Бесспорно, что размещение органов и учреждений субъектов Российской Федерации не всегда связано с территорией данного субъекта. Наиболее наглядный пример - представительство субъекта Федерации в Москве. Но и юрисдикция государства распространяется на морские и воздушные суда, территории посольств, находящихся за пределами государственной границы.

Естественно и то, что размещения региональных институтов, инфраструктуры и иных объектов субъекта Федерации также не на сто процентов сконцентрировано на его территории. Но и определение пространственных пределов размещения национальных институтов далеко не всегда связано с границами государства. Промышленные производства наиболее развитых экономик мира, как правило, располагаются за пределами территории соответствующего государства. В связи с этим территория национальной или региональной экономики может быть и шире, и уже территории государства или его региона.

Кроме того, пространственное размещение экономики далеко не всегда связано с территорией, что обусловлено развитием безналичных расчетов и электронных денег. Кроме того, система Интернет представляет собой огромный рынок различных услуг и технологий, которые также не имеют территориальной привязки. Следовательно, даже материальная часть национальной или региональной экономики не вся связана с территориальным пространством, динамично растущая ее часть относится к пространству электронному (виртуальному).

Информирование о принадлежности территории субъекту Федерации связано главным образом не с наглядными знаками на местности, а с распространением географических карт в бумажном и электронном видах, изучением соответствующих дисциплин. Так, в отношении границ государств, большинство людей пограничных знаков не видит, пересекая границы по воздуху или воде. Межевые знаки границ субъектов Федерации более доступны для обозрения граждан, потому они должны обязательно быть установлены по транспортным магистралям. Информирование граждан о прохождении и изменении границ субъектов Федерации имеет существенное значение и является задачей органов государственной власти субъектов Российской Федерации.

Охрана границ субъектов Федерации исключает меры военного характера. Граница субъекта Федерации не может стать «заградительным барьером», что необходимо в отношении государственной границы. Но ее охрана выражается в действиях политико-правового характера, юридическом оформлении границы, всем комплексе правовых, экономических, информационных средств. От обеспечения сохранности границ субъектов Федерации зависит осуществление местного самоуправление, соблюдение прав и законных интересов граждан и юридических лиц при определении границ земельных участков, арендуемых ими или находящимися в собственности.

Конституционные нормы об изменении границ субъектов федерации на основе их взаимного согласия, очевидно, предполагают, что эти границы когда-то и кем-то были установлены. Это было сделано в разное время и разными способами. Соответствующие границы, как правило, нормативно установлены еще до распада CCCP, на что прямо указывается, в частности, в части 1 статьи 2 Устава Белгородской области, в статье 10 Устава Курганской области. При этом в большинстве случает границы субъектов Российской Федерации не обозначены на местности должным образом.

Как отмечалось выше, пространственные пределы территории субъекта Российской Федерации определяются границами субъекта Федерации. Необходимость четкого правового и фактического определения границ субъектов Российской Федерации обусловлена задачей определения территории распространения юрисдикции органов государственной власти субъектов Федерации и органов местного самоуправления. Кроме того, от решения вопросов установления границ субъектов Российской Федерации зависит решение вопросов государственной и муниципальной собственности на землю и иные объекты недвижимости, связанных с нахождением этих объектов в пределах территории того или иного субъекта Федерации.

Т.Я. Хабриева отмечает негативные последствия отсутствия делимитации границ субъектов Федерации, что влечет за собой неопределенность в использовании земель, расположенных в районах их прохождения. По ее мнению, необходимы правила установления границ, закрепленные законодательно. Прохождение границ должно учитывать фактически сложившееся землепользование, культурные связи, исторические особенности, промышленное производство и социальную инфраструктуру с тем, чтобы границей не «разрезались» земельные участки, населенные пункты, территории предприятий, и чтобы линии границы проходили с учетом мнения местного населения9.

Вместе с тем отсутствует определенность в вопросе об установлении пределов территорий субъектов Российской Федерации. Если в отношении границ муниципальных образований имеется широкий массив федеральных и региональных законодательных норм, то законодательное регулирование установления границ субъектов Федерации недостаточно, что препятствует эффективному территориальному развитию страны. При этом границы многих

\footnotetext{
9 Доклад на «круглом столе» 26 июня 2001 года в Институте государства и права РАН по теме: «Границы между субъектами Российской Федерации и их изменение» //Государство и право. 2002. № 2. С. 109-110.
} 


\section{Право и политика 1 (157) 2013}

субъектов Федерации не отмечены на местности, а также не во всех субъектах существуют приложения к Уставу с указанием границ. Более того, в некоторых субъектах Российской Федерации существуют значительные расхождения между топографическим закреплением границ в землеустроительных документах и их реальным прохождением на местности.

В результате субъекты Российской Федерации сегодня вынуждены ссылаться на нормативные акты РСФСР и СССР в отношении определения своих границ либо самостоятельно нормативно описывать прохождение границ исходя из сложившихся в регионе представлений. Все это позволяет говорить об упречности нормативно-правовой базы установления границ субъектов Российской Федерации.

В свою очередь нельзя впадать в иную крайность и предъявлять к нормативным правовым актам о границах субъектов Российской Федерации завышенные требования по аналогии к правовому установлению границ суверенных государств. Так, едва ли можно согласиться, что «в идеале, административные границы субъектов Федерации должны были быть ратифицированы федеральным конституционным законом, утверждающим договоры между субъектами федерации, подписанные соответствующими органами государственной власти субъектов о границах и размерах их территорий» ${ }^{10}$.

Полагаем, что вполне достаточно определения границ между субъектами Российской Федерации в тексте специального закона субъекта Российской Федерации и приложениях к нему с подробным описанием и картографическими материалами в случае, если прохождение границы не вызывает споров у сопредельных субъектов и совпадает в их законодательстве. В случае возникновения спора необходимо разрешить спор соглашением между субъектами Российской Федерации, утвержденном Советом Федерации Федерального Собрания Российской Федерации. Основой такого соглашения может стать выявление нормативных правовых актов по данному вопросу, принятых в предшествующие периоды истории, решение судебных либо согласительных органов или воля ныне проживающего в субъектах Российской Федерации населения, выраженная непосредственно или через органы государственной власти.

Предложение о том, что государственное признание границ может осуществляться и многосторонними межсубъектными договорами ${ }^{11}$ не может быть поддержано. Государственное признание выражается в соглашениях субъектов Российской Федерации по спорным вопросам при утверждении Советом Федерации. В иных случаях оно

\footnotetext{
${ }^{10}$ Орлова М.Ф. Указ. Соч. С. 83.

${ }^{11}$ Там же. С. 66.
}

выражается в нормативных правовых актах федерального и регионального уровней.

Государственное установление границ публично-территориальных образований предполагает определенную правовую процедуру. Соответствующая процедура складывается из двух дополняющих друг друга процессов: делимитации и демаркации.

Делимитация внутригосударственных границ государственно-территориальных образований означает описание в тексте нормативного правового акта, а также максимально точное непосредственное обозначение линии ее прохождения на специальных картах, составляющих неотъемлемую часть соответствующего нормативного правового акта. Демаркация такой границы представляет собой обозначение и оборудование границы на местности.

Требования обязательного заключения договора между внутригосударственного образованиями при их делимитации и составления специальных протоколов при демаркации (по аналогии с границами государств) представляются не только бессмысленными, но и несоответствующими принципам государственного единства и территориальной целостности суверенного государства.

Между процедурами делимитации и демаркации нередки существенные временные разрывы. Установленные в нормативных правовых актах границы длительное время не обозначаются на местности. Более того, в отношении многих участков границ субъектов Российской Федерации, а также их административно-территориальных единиц, муниципальных образований демаркации не произошло до настоящего времени.

Помимо юридического определения и установления границ на местности делимитация и демаркация означают государственное признание границ субъектов Российской Федерации. При их отсутствии речь может идти о существующих или потенциальных территориальных спорах. Следует согласиться, что в процессе регламентации прохождения внутригосударственных границ было бы целесообразно руководствоваться принципами концепции «эстоппеля», которая нашла свое закрепление в современном международном праве. В соответствии с данной концепцией государство должно быть последовательно и не отрицать уже признанного факта. ${ }^{12}$ Тогда алгоритм решения территориального спора сводился бы к необходимости выяснить линию прохождения границы, ранее признанную Российским государством. В случае обнаружения такого признания спор разрешался бы автоматически.

Необходимо подчеркнуть, что субъекты Федерации в настоящее время не вполне справляются с задачей качественного правового оформления прохождения границ между субъектами Российской Федерации.

\footnotetext{
${ }^{12}$ Там же. С. 67.
} 
Основные недостатки в правом регулировании установления границ субъектов Российской Федерации можно свести к следующим.

1. Эклектичность. Субъекты Российской Федерации ссылаются на разные по форме нормативные правовые акты, устанавливающие границы между ними (включая акты СССР и РСФСР), содержащие необходимое регулирование в неодинаковом объеме.

2. Низкая юридическая техника. Далеко не во всех нормативных правовых актах, устанавливающих прохождение границы субъекта Российской Федерации содержится подробное описание границ, а также картографическое приложение.

3. Неинформативность. Даже в справочных правовых системах тексты нормативных правовых актов, устанавливающих границы между субъектами, содержащими их описание не имеют картографических приложений. В свою очередь, учебные и справочные географические издания не являются официальными. В связи с этим не только граждане, но и официальные структуры вынуждены опираться на справочные издания, т.е. неофициальные источники информации о прохождении границ между субъектами российской Федерации, что изначально закладывает возможность возникновения проблем вследствие ошибочности определения прохождения границ в их действиях и решениях.

4. Конфликтность. Одностороннее несогласованное описание субъектом Российской Федерации прохождения его границы с другим субъектом в своем нормативном правовом акте всегда оставляет поле для конфликта о прохождении границы, поскольку нормативный правовой акт сопредельного субъекта может содержать отличное описание. Так, Закон Ивановской области от 29 апреля 2002 года № 24-О3 (в ред. от 03.03.2011 г.) «Об утверждении описания границы Ивановской области» оспаривался законодательным органом Костромской области в Конституционном Суде РФ.

Вопросы описания прохождения границ субъектов Российской Федерации опосредованно решаются посредством законодательного определения границ муниципальных образований, входящих в состав субъекта Федерации. Поскольку внешние границы ряда муниципальных образований совпадают с границами субъекта Федерации, опосредованно оформляется и данная разновидность внутригосударственных границ. В одних субъектах Федерации принимаются законы об описании границ каждого муниципального образования, в других сразу всех муниципальных образований, прежде всего муниципальных районов и городских округов. Так, приняты Законы Ивановской области от 11 января 2005 года № 3-О3 (в ред. от 01.02.2012 г.) «Об утверждении описаний границ существующих муниципальных районов и городских округов»; Забайкальского края от 18 декабря 2009 года
№ 317-3ЗК (ред. от 07.11.2011 г.) «О границах сельских и городских поселений Забайкальского края»; города Москвы от 15 октября 2003 года № 59 (в ред. от 11.04.2012 г.) «О наименованиях и границах внутригородских муниципальных образований в городе Москве». В ряде субъектов Федерации, прежде всего в республиках, предприняты попытки включить в предмет законов не только описание границ, но и определение статуса муниципальных образований. Это едва ли продуктивно, поскольку данный вопрос решен в Федеральном законе № 131-ФЗ. Субъектам Российской Федерации остается лишь воспроизводить его нормы, что загромождает правовой массив в данной сфере. В частности, данный недостаток характерен для действующих Законов Республики Бурятия от 31 декабря 2004 года № 985-III (в ред. от 23.12.2011 г.) «Об установлении границ, образовании и наделении статусом муниципальных образований в Республике Бурятия»; Республики Дагестан от 13 января 2005 года № 6 (в ред. от 12.03.2012 г.) «О статусе и границах муниципальных образований Республики Дагестан»; Республики Ингушетия от 23 февраля 2009 года № 5-Р3 (в ред. от 29.03.2010 г.) «Об установлении границ муниципальных образований Республики Ингушетия и наделении их статусом сельского поселения, муниципального района и городского округа».

В целом полагаем, что описание границ муниципальных образований не является заменой описанию границ субъекта Российской Федерации, несмотря на совпадение таких границ на участках, сопредельных с иными субъектами Российской Федерации. Ведь Государственная граница Российской Федерации тоже совпадает с границами субъектов Российской Федерации, но это не является основанием для пренебрежения к правовому оформлению Государственной границы. Более того, именно описание прохождения Государственной границы России как государства, в состав которого входят субъекты Российской Федерации, выступает определяющим фактором прохождения границ субъектов Федерации.

Кроме того, в части 3 статьи 10 Федерального закона № 131-Ф3 установлено, что при изменении границ между субъектами Российской Федерации требования статей 12 и 13 данного Федерального закона не применяются. В этом случае изменение границ муниципальных образований, преобразование муниципальных образований, их упразднение, связанные с изменением границ между субъектами Российской Федерации, осуществляются в порядке, установленном законами субъектов Российской Федерации. Таким образом, федеральный законодатель признал приоритетность прохождения границы субъекта Федерации перед прохождением границы муниципального образования.

В связи с этим и описание границ субъекта Российской Федерации должно стать основой для определения границ муниципальных образований и административно-терри- 


\section{Право и политика $1(157) \cdot 2013$}

ториальных единиц данного субъекта Федерации. Пока же происходит обратная ситуация. Регионы имеют меньше реальных гарантий определенности прохождения их границ не только по сравнению с Российской Федерацией (что объективно предопределено соотношением статусов Государственной границы и внутригосударственных границ), но и с муниципальными образованиями. В отношении статуса границ муниципальных образований имеются и конституционные установления ${ }^{13}$, и развернутое федеральное законодательное регулирование, и региональное законодательное обеспечение.

Оптимальным видится принятие специальных законов об описании границ именно субъекта Федерации. В частности, речь идет о Законах Астраханской области от 12 апреля 2004 года № 21/2004-О3 (в ред. от 31.10.2011 г.) «Об утверждении описания границы Астраханской области»; Ивановской области от 29 апреля 2002 года № 24-О3 (в ред. от 03.03.2011 г.) «Об утверждении описания границы Ивановской области». К сожалению повышенное внимание к законодательному оформлению границ региона характерно для тех субъектов Российской Федерации, в отношении территории которых имеются устойчивые притязания со стороны сопредельных субъектов Федерации. В свою очередь невнимание приводит к возникновению споров, что провоцирует активность в данном вопросе. Но ее было бы лучше проявить до возникновения спорных ситуаций.

В Конституции РФ и федеральном законодательстве отсутствуют правовые нормы, определяющие, каким правовым актом должны были быть установлены границы субъектов Российской Федерации. Полагаем, что это необходимо сделать на уровне федерального закона. Соответствующим нормативно-правовым актом видится специальный закон субъекта Российской Федерации, с обязательным приложением, содержащим картографическое и словесное описание прохождения границы субъекта Федерации. Такой закон целесообразно размещать в справочных правовых системах вместе с описанием и картографическим приложением, а сами официальные приложения официально издавать и распространять среди органов публичной власти, организаций и населения.

\section{Библиография:}

1. «Границы между субъектами Российской Федерации и их изменение» («Круглый стол») // Государство и право. 2002. № 2.

2. Клименко В.М., Порк А.А. Территория и граница CCCP. 1985.

3. Лопатин В.В., Лопатина Л.Е. Русский толковый словарь. М., 1997.

4. Орлова М.Ф. Территория и границы субъекта Российской Федерации (на примере Астраханской области). Дис. кандидата юридических наук. М., 2002.

5. Постатейный комментарий к Конституции Российской Федерации / Под общ. ред. Ю.В. Кудрявцева. М., 1996.

6. Ушаков Н.А. Международное право: основные термины и понятия. М.: ИГЛ РАН. 1996.

7. Чертков А.Н. Правовое регулирование территориального устрйоства России: концепция и прогноз. Дис. доктора юридических наук. М., 2012.

8. Энциклопедический словарь, том IX / Издатели: Ф.А.Брокгауз, И.А.Ефрон, Санкт-Петербург, 1898.

\section{References (transliteration):}

1. Klimenko V.M., Pork A.A. Territoriya i granitsa SSSR. 1985.

2. Lopatin V.V., Lopatina L.E. Russkiy tolkovyy slovar'. M., 1997.

3. Orlova M.F. Territoriya i granitsy sub'ekta Rossiyskoy Federatsii (na primere Astrakhanskoy oblasti). Dis. kandidata yuridicheskikh nauk. M., 2002.

4. Yu.V. Kudryavtsev. Postateynyy kommentariy k Konstitutsii Rossiyskoy Federatsii / Pod obshch. red. Yu.V. Kudryavtseva. - M., 1996.

5. Ushakov N.A. Mezhdunarodnoe pravo: osnovnye terminy i ponyatiya. M.: IGL RAN. 1996.

6. Chertkov A.N. Pravovoe regulirovanie territorial'nogo ustryostva Rossii: kontseptsiya i prognoz. Dis. doktora yuridicheskikh nauk. M., 2012.

\footnotetext{
${ }^{13}$ Статья 131 (часть 2) Конституции РФ, согласно которой изменение границ территорий, в которых осуществляется местное самоуправление, допускается с учетом мнения населения соответствующих территорий.
} 